\section{Chloride losing diarrhoea and metabolic alkalosis in an infant with cystic fibrosis}

Large intestinal losses of chloride have been reported in infants after bowel surgery (Aaronson, 1971) and in the syndrome of 'congenital alkalosis with diarrhoea' (Davidson et al., 1972). Metabolic alkalosis in a case of cystic fibrosis developed during a period of excessive ileostomy drainage with a high chloride content.

\section{Case report}

A female born at term, birthweight $2950 \mathrm{~g}$, developed signs of intestinal obstruction. She was operated within 24 hours of delivery, and the findings were compatible with meconium ileus. A heavily inspissated $10 \mathrm{~cm}$ portion of the distal ileum was resected and end-to-side anastomosis, distal ileostomy, and gastrostomy were performed. Recurrence of abdominal distension required laparotomy 36 hours later. An internal hernia was reduced and a Mikulicz type double-barrel ileostomy was created proximal to the previous anastomosis. The early postoperative course was further complicated by moderate respiratory distress, production of copious amounts of tenacious sputum, and a left lower lobe atelectasis. Sweat electrolytes (on day 10 of life) were $\mathrm{Na} 78 \mathrm{mEq} / \mathrm{l}, \mathrm{K} 12 \mathrm{mEq} / \mathrm{l}$, and $\mathrm{Cl} 115$ $\mathrm{mEq} / \mathrm{l}$. Postoperative serum electrolytes were $\mathrm{Na} 139$ $\mathrm{mEq} / \mathrm{l}, \mathrm{K} 4.4 \mathrm{mEq} / \mathrm{l}, \mathrm{Cl} 97 \mathrm{mEq} / \mathrm{l}$, and $\mathrm{HCO}_{3} 25 \mathrm{mEq} / 1$ while on parenteral maintenance fluids.

The introduction of Nutramigen via gastrostomy was initially well tolerated. The daily gastrostomy feeds were gradually increased to $530 \mathrm{ml}$. resulting in a watery ileostomy drainage of up to $750 \mathrm{ml}$ per day and intermittent dehydration. Parenteral correction was evidently incomplete with a weight loss of $600 \mathrm{~g}$ within 10 days. Serum electrolytes showed the pattern of persistent metabolic alkalosis: $\mathrm{Na} 132 \mathrm{mEq} / \mathrm{l}, \mathrm{K} 4 \cdot 1$ $\mathrm{mEq} / 1, \mathrm{C} 170 \mathrm{mEq} / 1, \mathrm{HCO}_{3} 40 \mathrm{mEq} / 1$, venous $p \mathrm{H} \mathrm{7} \cdot 51$, and $\mathrm{PCO}_{2} 40 \mathrm{mmHg}$. Further investigations showed low normal serum sodium levels, normal potassium, and chloride in the range of $60-80 \mathrm{mEq} / \mathrm{l}$. Blood urea nitrogen was normal or high-normal with dehydration. Spot urines gave Na $13-37 \mathrm{mEq} / 1, \mathrm{~K}$ 35-49 mEq/1, and $\mathrm{C1}$ 4-17 m Eq/1. Urinary $p \mathrm{H}$ varied between $5 \cdot 0$ and $8 \cdot 0$. The chloride, sodium, and potassium content of the ileostomy fluid was analysed on eight different occassions. Chloride averaged $99 \mathrm{mEq} / 1$ (range 78-118), sodium $80 \mathrm{mEq} / 1$ (range 70-92), and potassium 14 $\mathrm{mEq} / \mathrm{l}$ (range 11-16). The stools were Clinitest positive and had a $p \mathrm{H}$ of $6 \cdot 0$.
Discontinuation of gastrostomy feeds and administration of intravenous fluids $(480 \mathrm{ml}$ of $1 / 3$ to $1 / 2$ isotonic saline with $7 \mathrm{mmol}$ potassium chloride/day) led to a rapid normalization of serum electrolytes (Na 138, K 3.9, $\mathrm{Cl} 101, \mathrm{HCO}_{3} 25 \mathrm{mEq} / \mathrm{l}$ ). Spot urines gave $\mathrm{Na} 50, \mathrm{~K} \mathrm{4} \cdot 2, \mathrm{C} 150 \mathrm{mEq} / \mathrm{l}$, and the ileostomy drainage was minimal. A brief discontinuation of intravenous fluids and resumption of enteral feeding (Nutramigen or Pregestimil) resulted in recurrence of metabolic alkalosis.

Serum electrolytes were normal during a 7-week period of parenteral alimentation. An attempt to supplement the latter by gastric feeds produced a watery ileostomy drainage with electrolyte composition as above. After a satisfactory weight gain, the ileostomy was closed and the parenteral alimentation line removed. The infant continued to gain weight on an oral formula supplemented by viokase. The stools were poorly formed and moderately bulky. The electrolyte content was not determined. Serum electrolytes remained normal. The child was subsequently followed up by a cystic fibrosis clinic.

\section{Discussion}

Recent studies (Schwartz, Van Ypersele De Strihou, and Kassirer, 1968; DeSousa et al., 1974) indicate that the two factors primarily responsible for the development of metabolic alkalosis via renal tubular mechanisms are (1) the diversion of sodium to distal tubular exchange sites, and (2) the avidity of these exchange sites for sodium. The diversion of sodium into the distal nephron is facilitated by the prevalence in the proximal tubule of endogenous or exogenous anions with relatively (to chloride) poor resorption ability. This would be the case in clinical and experimental hypochloraemia, whether absolute such as in gastric loss of hydrochloric acid or diarrhoeal loss of chloride, or relative, such as in the adminisstration of equimolar amounts of hydrogen ions with sulphate or nitrate instead of chloride as anions. With sodium deficiency and contraction of extracellular fluid volume, distal sodium for potassium and hydrogen exchange is stimulated, and the second requirement for the development of metabolic alkalosis is fulfilled. Potassium deficiency alone is now being regarded as a result of the enhanced distal sodium for cation exchange rather than as a causal factor for the development of metabolic alkalosis. The administration of potassium without chloride may not correct the alkalosis. 
The syndrome of chloride losing diarrhoea and metabolic alkalosis has been recently reviewed by Davidson et al., (1972). The following pattern is thought to characterize this condition: severe watery diarrhoea with a stool chloride content of 70-150 mEq/1 faecal fluid, minimal, or no urinary chloride excretion, severe hypochloraemia, hyponatraemia, and hypokalaemia of variable degree, hypovolaemia and metabolic alkalosis. Paradoxical aciduria occurs in the presence of severe potassium depletion. Correction is brought about by fluid and electrolyte therapy and potassium chloride supplements. Potassium with an anion other than chloride appears to be ineffective.

Large losses of chloride have also been reported in infants with ileostomy or colostomy after bowel surgery (Aaronson, 1971). Severe watery diarrhoea was associated with faecal chloride concentrations often exceeding $100 \mathrm{mEq} / 1$ of stool water, similar or slightly lower faecal sodium, and minimal faecal potassium concentrations. The infants required fluid and electrolyte therapy. No acidbase abnormalities were mentioned under these circumstances.

Our data may now be discussed in this context. The patient developed hypochloraemic alkalosis during a period of excessive watery ileostomy drainage. Although balance studies were not available, the amount and electrolyte content of the ileostomy fluid suggested that it was a major source of fluid, chloride, and some degree of sodium depletion. The low urinary chloride content was suggestive of an extrarenal loss of chloride. With intermittent dehydration and continuous weight loss, parenteral fluid and electrolyte therapy was evidently insufficient as long as the cycle of copious enteral feedings and diarrhoea was maintained. Cessation or reduction of enteral feedings minimized the ileostomy drainage and corrected the electrolyte imbalance in a reversible manner. Metabolic alkalosis did not recur after the closure of ileostomy, resumption of oral feeds, and discontinuation of parenteral nutrition. It appears that in the presence of hypochloraemia and of a sodium avid state, the criteria for the development of metabolic alkalosis have been met. There was no evidence of potassium depletion.

Metabolic alkalosis has been reported in cystic fibrosis with heat prostration, severe dehydration, and salt depletion (Kessler and Andersen, 1951; Rendle-Short, 1956; Di Sant' Agnese, 1960; Gottlieb, 1971; Arvantitakis and Lobeck, 1973). It is tempting to speculate that excessive sweat losses of chloride, sodium, and potassium, especially if superimposed upon pre-existing fluid and electrolyte depletion, could easily create the abovementioned optimal conditions for the genesis of metabolic alkalosis. Gastric loss of hydrochloric acid, however, might have played a predominant role in some of these reports (Kessler and Andersen, 1951; Di Sant' Agnese, 1960; Arvantitakis and Lobeck, 1973) and intestinal loss of chloride appears to be a plausible explanation in our case. Careful clinical evaluation and balance studies would be required to show a more than coincidental correlation between cystic fibrosis and metabolic alkalosis.

\section{Summary}

A case of hypochloraemic metabolic alkalosis in an infant with chloride losing ileostomy drainage and cystic fibrosis is described. It is speculated that intestinal loss of chloride played a major role in the development of metabolic alkalosis.

\section{REFERENCES}

Aaronson, I. (1971). Secondary chloride-losing diarrhoea Archives of Disease in Childhood, 46, 479.

Arvantitakis, S. N., and Lobeck, C. C. (1973). Metabolic alkalosis and salt depletion in cystic fibrosis. (Letter.) fournal of Pediatrics, 82, 535.

Davidson, A. G. F., Insley, J., Capps, F. P. A., and Anderson, C. M. (1972). Familial chloride diarrhoea. Australian Paediatric fournal, 8, 187.

DeSousa, R. C., Harrington, J. T., Ricanati, E. S., Shelkrot, J. W., and Schwartz, W. B. (1974). Renal regulation of acid-base equilibrium during chronic administration of mineral acid. Fournal of Clinical Investigation, 53, 465.

Di Sant' Agnese, P. A. (1960). Salt depletion in cold weather in infants with cystic fibrosis of the pancreas. Fournal of the American Medical Association, 172, 2014.

Gottlieb, R. P. (1971). Metabolic alkalosis in cystic fibrosis. Fournal of Pediatrics, 79, 930.

Kessler, W. R., and Andersen, D. H. (1951). Heat prostration in fibrocystic disease of the pancreas and cther conditions. Pediatrics, 8, 648.

Rendle-Short, J. (1956). Fibrocystic disease of the pancreas presenting with acute salt depletion. Archives of Disease in Childhood, 31, 28.

Schwartz, W. B., Van Ypersele De Strihou, C., and Kassirer, J. P. (1968). Role of anions in metabolic alkalosis and potassium deficiency. New England fournal of Medicine, 279, 630.

H. I. Hochman, ${ }^{\star}$ N. R. Feins, R. Rubin, and J. Gould

Department of Pediatrics, Boston City Hospital, Boston University School of Medicine, 818 Harrison Avenue, Boston, Mass. 02118, USA.

*Correspondence to Dr. H. I. Hochman.

\section{Immunoglobulin $\mathrm{E}$ in erythema nodosum}

Serum immunoglubulin $\mathrm{E}$ is characteristically increased in various atopic conditions (Johansson, 1967; Havnen et al., 1973), sometimes as much as 